Session 3659

\title{
DEVELOPMENT OF A MEASUREMENT SYSTEM FOR RESPONSE OF A SECOND ORDER DYNAMIC SYSTEM
}

\author{
Dr. Peter Avitabile, Assistant Professor \\ Charles Goodman, Graduate Student \\ Tracy Van Zandt, Undergraduate Student \\ Mechanical Engineering Department \\ University of Massachusetts Lowell \\ One University Avenue \\ Lowell, Massachusetts USA \\ Peter_Avitabile@uml.edu
}

\begin{abstract}
Designing a measurement system for a specific application can be a daunting task. A 2nd order mechanical system (cantilever beam) is presented to the Mechanical Engineering Laboratory II student groups. They are to measure the dynamic response at three non-colocated measurement points. The students are required to select three different types of measurement devices (from several possible transducers), determine suitable locations, digital data acquisition requirements, etc. to determine the "best" method to address the problem. All measurements must be compared to each other. This requires spatial adjustment as well as integration/differentiation of displacement, velocity and acceleration measurements; these may be acquired from an LVDT, accelerometer, laser, eddy current probes, strain gage, etc). The use of a dynamic system model (using MATLAB and/or SIMULINK) to determine the actual response due to impulsive and step loading is required. The optimization of the parameters (signal type, location, transducer sensitivity, etc) is required to provide the "maximum" signal for the ADC specified for the data acquisition. A full formal report is prepared to document all aspects of the project effort along with a formal presentation. The details of the project along with some results obtained from various student groups is also presented.
\end{abstract}

\section{Introduction}

Laboratory experiments are an excellent opportunity for students to provide real-world practical solutions to problems that may not have an "answer at the back of the book". Students learn best with hands-on projects and problems with practical purpose [1]. These types of problems tend to 
be challenging for both the student and professor. Students must be afforded the experience of problems that require them to formulate solutions to problems with no specific straight-line structure to the solution - they must learn how to "think outside the box" [2].

The mission for all instructors is to educate their students in the most efficient manner possible. Teaching techniques should challenge, educate, and promote innovative thinking from students. The lecture-based format of teaching which predominates in engineering education may not be the most effective manner to achieve these goals $[3,4]$. Constructivist learning theory asserts that knowledge is not simply transmitted from teacher to student, but is actively constructed by the mind of the learner through experiences. [5,6].

The laboratory environment is an excellent opportunity to force the students to "think on their own". Real-world laboratory exercises and experimental approaches clearly show that there is not always an "answer at the back of the book". While students at times become frustrated by this, they learn that they need to employ many of their STEM (Science, Technology, Engineering, Mathematics) skills in order to solve even the simple problems. Industry advisors have clearly identified the need for students to be exposed to a real-world laboratory environment where modern instrumentation and computers interface in performing data acquisition and data reduction $[7,8,9]$.

Experiments play a very critical role in validating analytical models and hypotheses. Students must feel comfortable in a laboratory environment and must not feel foreign to lab equipment, instrumentation, etc. Students must also feel comfortable formulating solutions to real engineering problems using all of the STEM tools available to them. The STEM tools must become an integral part of their learning process throughout their entire educational and professional careers - the students must, in essence, "live the material" every day and in every course.

In laboratory courses, students are expected to understand and comprehend all of the prerequisite STEM material. Laboratory courses generally have some review material to summarize the basic underlying theory and methodology required for particular laboratories. The laboratory course can then concentrate on various measurement techniques.

In the Mechanical Engineering Department at UMASS Lowell, the laboratory courses are taught in a two semester sequence. The first semester concentrates mainly on basic measurement tools (oscilloscopes, multimeters, digital data acquisition, etc), measuring devices (flow meters, manometers, pressure transducers/gages, pitot tubes, strain gages, thermocouples, accelerometers, LVDTs, etc) and methods for data collection/reduction (regression analysis, curvefitting, numerical processing). The first semester has many different labs which, in general, are intended to get the students exposed to the overall mechanical measurement world. However, there are a few labs which are intended to force the students to work through several difficult issues. The second semester is split into two halves. The first half continues the more structured lab environment but introduces more complicated labs and concepts including fourier domain processing techniques with FFT analyzers. The second half of the semester concentrates on the student development of a measurement system. The students are given only vague 
specifications for the overall measurement requirements and they must formulate a measurement system to achieve the require goals.

This paper addresses one of the final lab projects from the second semester sequence of Mechanical Engineering Laboratory. The project involves the development of a measurement system for the response of a second order dynamic system and is discussed below.

\section{Development of a Measurement System for a $2^{\text {nd }}$ Order Dynamic System}

The problem is posed as a measurement system to determine the tip response of a disk drive armature unit due to arbitrary loadings; the disk drive armature is considered to be approximated as a simple cantilevered structure. The students are to make measurements on a cantilevered beam structure shown in Figure 1 (which is a conceptual representation of the disk drive armature). The students are given general guidelines regarding the measurment system to be developed. The students are required to select three non-colocated different measurement devices from five possible transducers such as LVDT, accelerometer, laser, eddy current probes, and strain gages. They must determine suitable locations for the transducers, identify digital data acquisition (DAQ) requirements, etc. to determine the "best" method to address the problem. Ultimately, they are to predict the dynamic response at the tip of the beam.

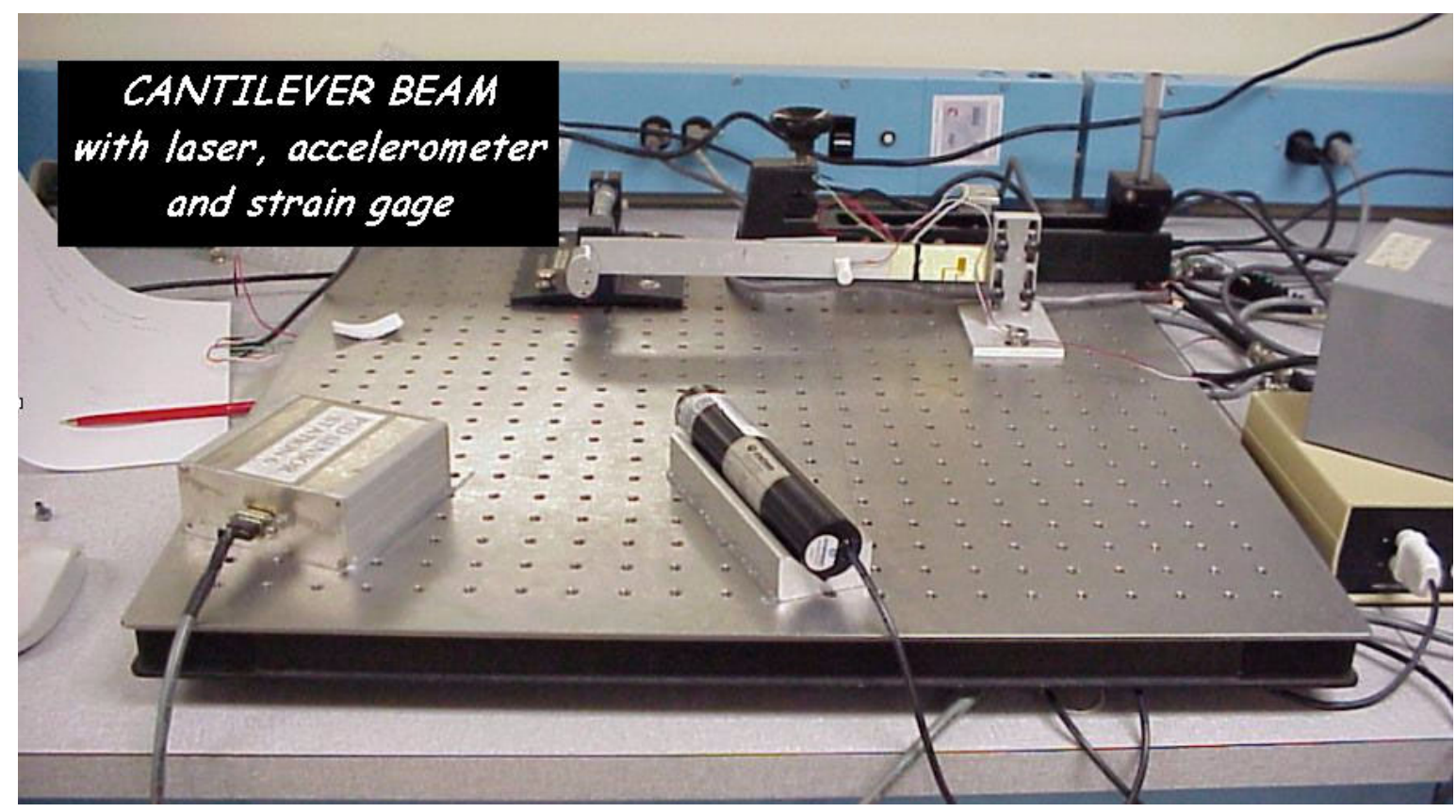

Figure 1 - Photo of a Typical Measurement Setup

Measurements from all three devices must be compared to each other which requires spatial adjustment as well as integration/differentiation of displacement, velocity and acceleration measurements. The use of dynamic system models to determine actual response due to arbitrary 
loading is required (using MATLAB and/or SIMULINK). The optimization of the parameters (signal type, location, transducer sensitivity, etc) is required to provide the "maximum" signal for the ADC specified for the data acquisition. A full formal report is prepared to document all aspects of the project effort along with a formal presentation.

\section{II.1 Brainstorming}

The first step for the students is to brainstorm the problem and attempt to determine suitable transducers for the measurement system. Usually, a trip to the lab to take several exploratory measurements yields useful information. The students quickly realize that some of the measurement locations produce suitable measurements for some of the available transducer types while other transducers initially selected have insufficient resolution or dynamic range for adequate measurements of the system. They struggle with a variety of concepts including spatial correlation of non-colocated transducers, comparison of acceleration and displacement and strain measurements, and so on.

Very quickly, the students realize that they must "engineer the problem" to clearly identify the specific measurement transducers that will provide the best signal depending on spatial location of the transducer on the cantilever beam.

\section{II.2 I Didn’t Think We Needed to Know Stuff from Other Courses !}

The students initially believe that all they need to do is make some measurements, calibrate transducers and write a final report. Ah - if life could be that easy! The students generate simple models of their cantilever system to predict the expected reponse spatially along the length of the beam in terms of displacement, velocity, acceleration, strain, etc. depending on the types of transducers they intend to employ. Of course, the understanding of statics, strength of materials, dynamic systems, ordinary differential equations, numerical methods, etc. all start to come into play at this point. (Hey --- I thought this was just a lab course --- Why do I need to use and know all this other stuff from these other courses? --- I thought you were only allowed to ask me to do things that are related to lab???).

Once the initial shock wears off, the students realize that the project is much more encompassing than they would have ever imagined. The after-shock sends students running to an assortment of text books in related areas to assist in the development of a model for the prediction of the system response. After this initial stage, models are generally developed that assist in the prediction of voltage output as a spatial distribution along the length of the beam in an attempt to optimize the input levels to the digital data acquisition system. These models may consist of spreadsheet calculations or MATLAB/SIMULINK models for the predicted response. A typical SIMULINK model is shown in Figure 2. 


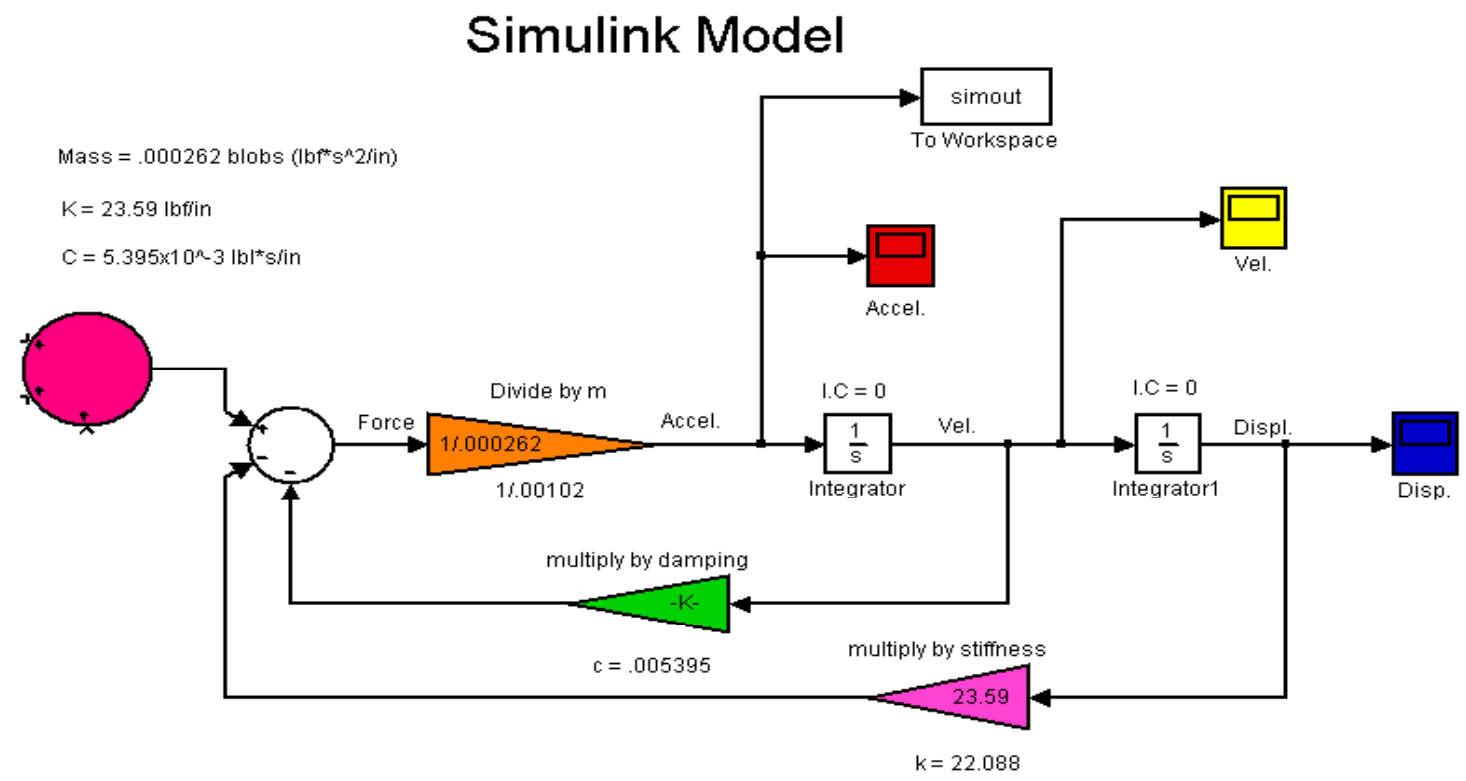

Figure 2 - Typical SIMULINK Model for Dynamic System Response

\section{II.3 Measurement Problems Encountered in Other Laboratory Exercises}

The processing of this data involves significant other challenges related to measurement problems (noise, DC bias, drift), digital data acquisition (quantization errors, sampling rate, AC coupling, etc) and numerical processing (integration/differentiation); these are serious problems that must also be addressed. Since the UMASS Lowell Mechanical Engineering Laboratory integrates all of the material covered in the ME Lab I \& II sequence, these items have been previously addressed. Reference 10 presents some of the issues pertaining to the processing of these types of measurement situations. Suffice it to say, the students are well prepared to address these additional concerns in the measurement process.

\section{II.4 The Real Work Begins}

Once the initial shock (and secondary shock) wears off, the students proceed with typical procedural steps to finalize the measurement system. Schematics of the test setup are constructed as seen in Figure 3. Procedures for calibration of equipment are developed and performed. Some typical calibration data is shown in Figure 4 for an LVDT and laser measurement system. Since an analytical model was developed for the "design" of the measurement system, some validation of the model is necessary. Students often use frequency response measurements, such as the one in Figure 5, to assure that the dynamic characteristics of the beam are correctly modeled. In addition, the LVDT signal is contaminated with $60 \mathrm{~Hz}$ noise. The students must design a simple RC, low pass filter circuit to eliminate this potential distortion 
of the data. A typical RC circuit used for this purpose along with its Bode plot is shown in Figure 6.

The goal is to obtain the displacement and acceleration at the tip of the cantilever. The transducers are not located at the same position nor at the end of the beam. The measurements may be displacement, velocity and/or acceleration. The real effort lies in the spatial adjustment and integration/differentiation of the measurements taken. A significant effort is needed to achieve this. The students must realize that material from related courses such as Numerical Methods, Strength of Materials, etc. is critical to the overall assessment of the problem. All of this is accomplished with some "pain and agony" along the way.

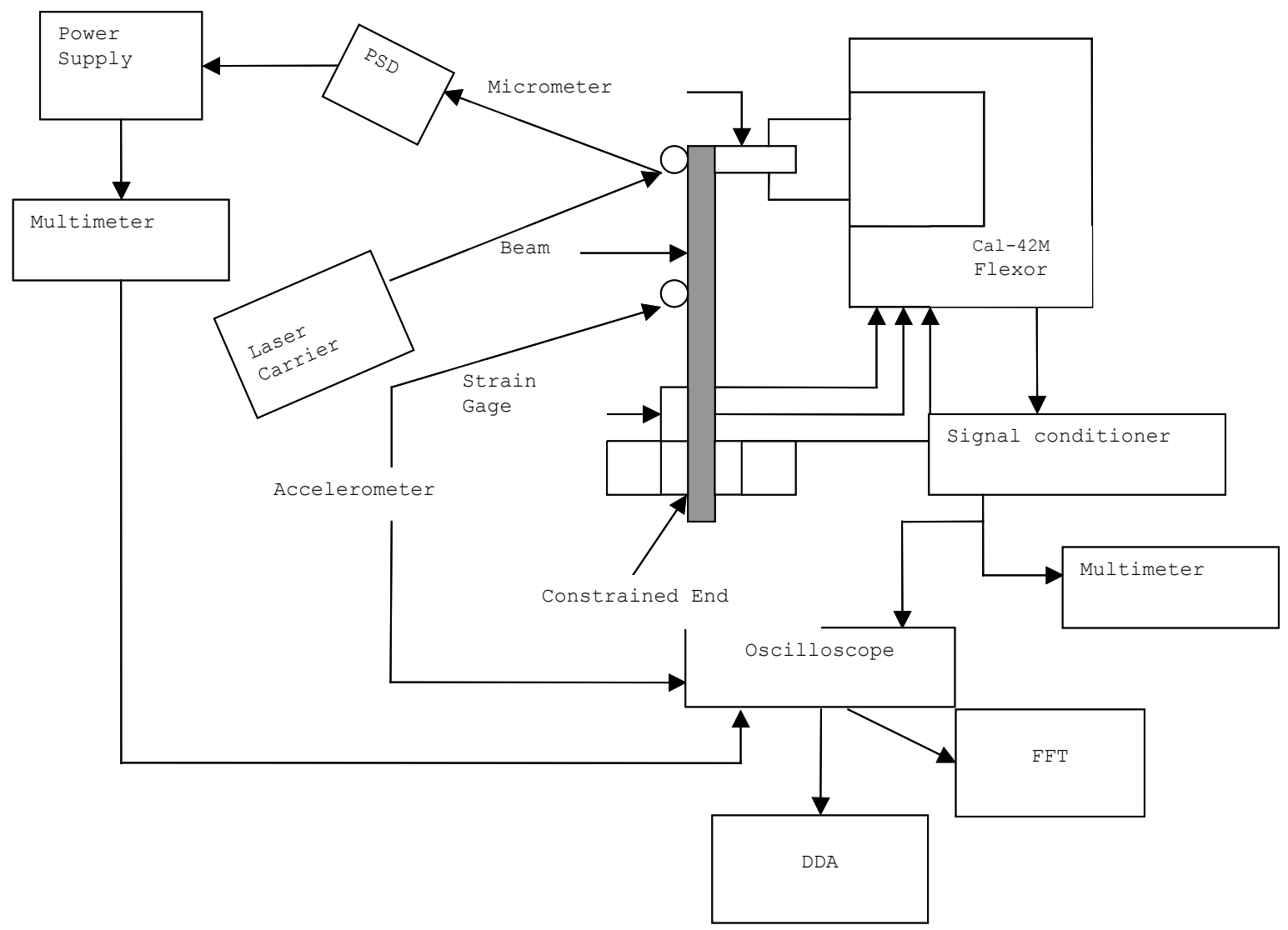

Figure 3 - Schematic of Measuring System for Dynamic System Response 


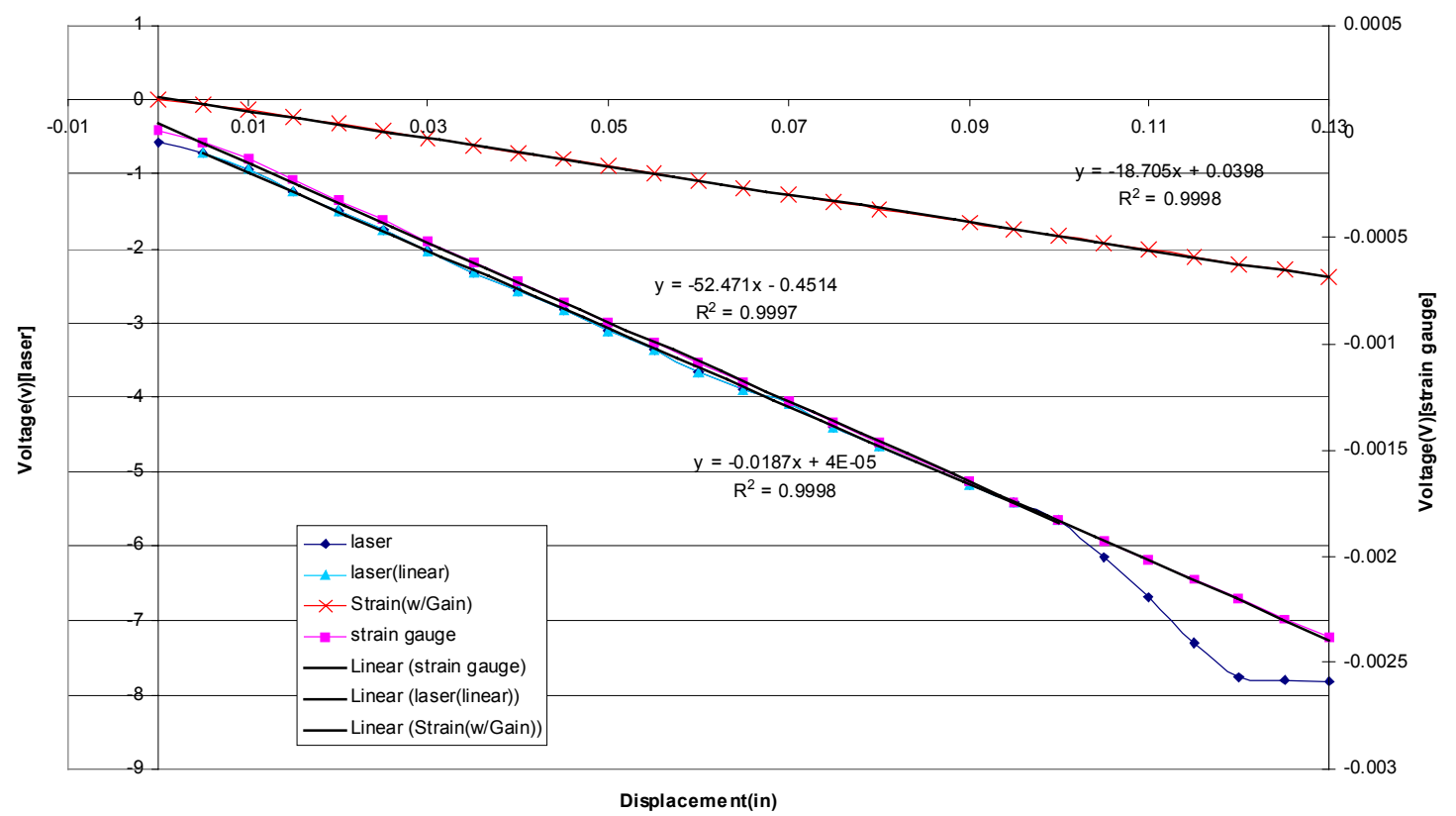

Figure 4 - Typical Calibration Data sets for Transducers Selected

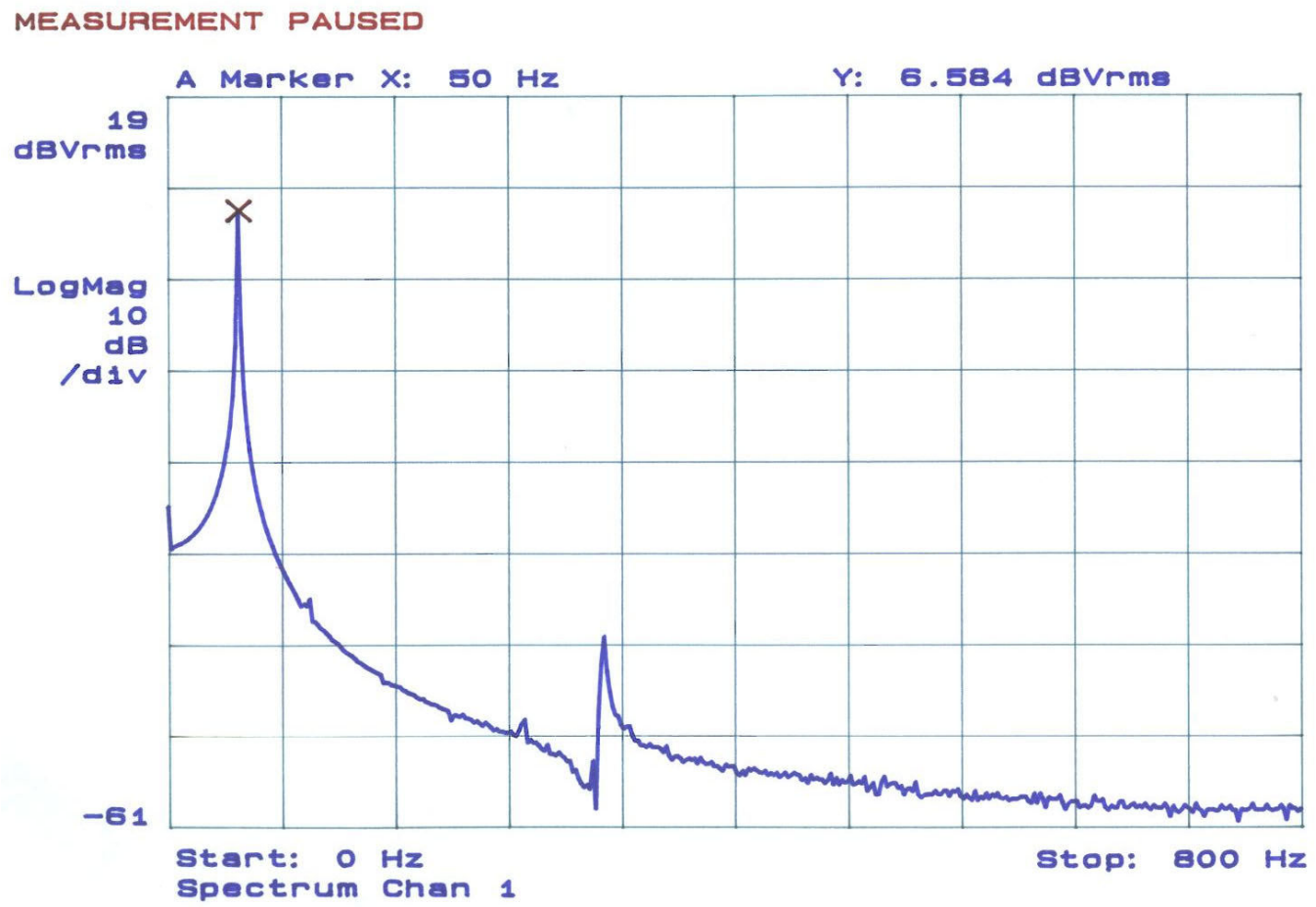

Figure 5 - Frequency Response Measurement for the Cantilever Beam System 


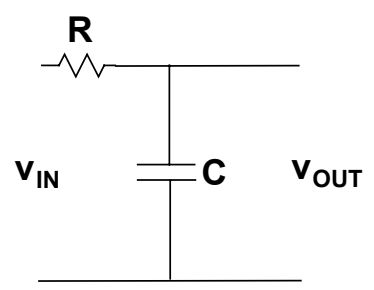

RC Circuit
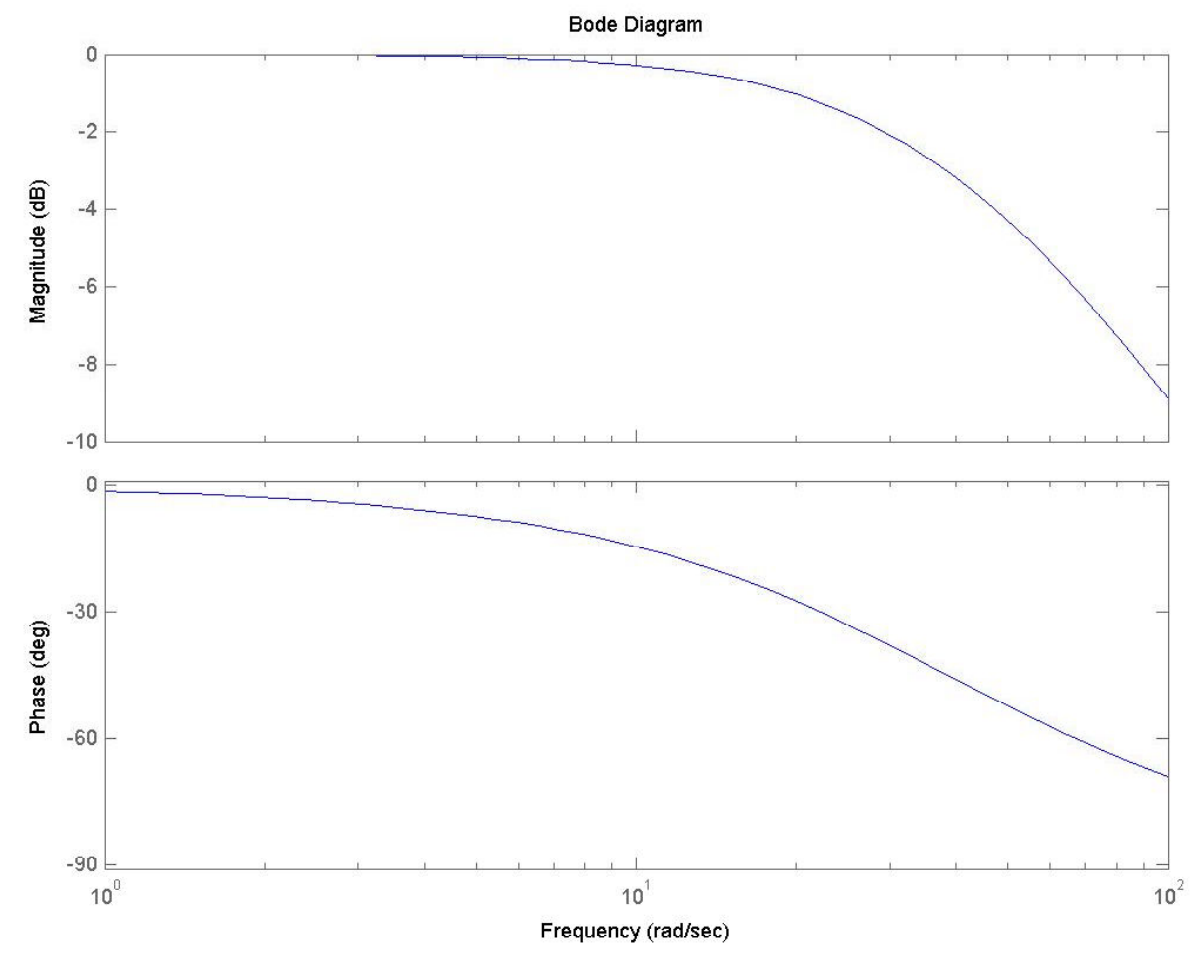

Bode Plot

Figure 6 -RC Circuit and Bode Plot of Low Pass Filter 


\section{II.5 The Results}

At the conclusion of the project, the groups present their models, assessments and results which predict the tip displacement and acceleration of cantilever beam. A typical "success" story is shown in Figure 7 which shows the overlay of data from a laser, strain gage and accelerometer used at three different non-colocated locations to predict the tip displacement response.

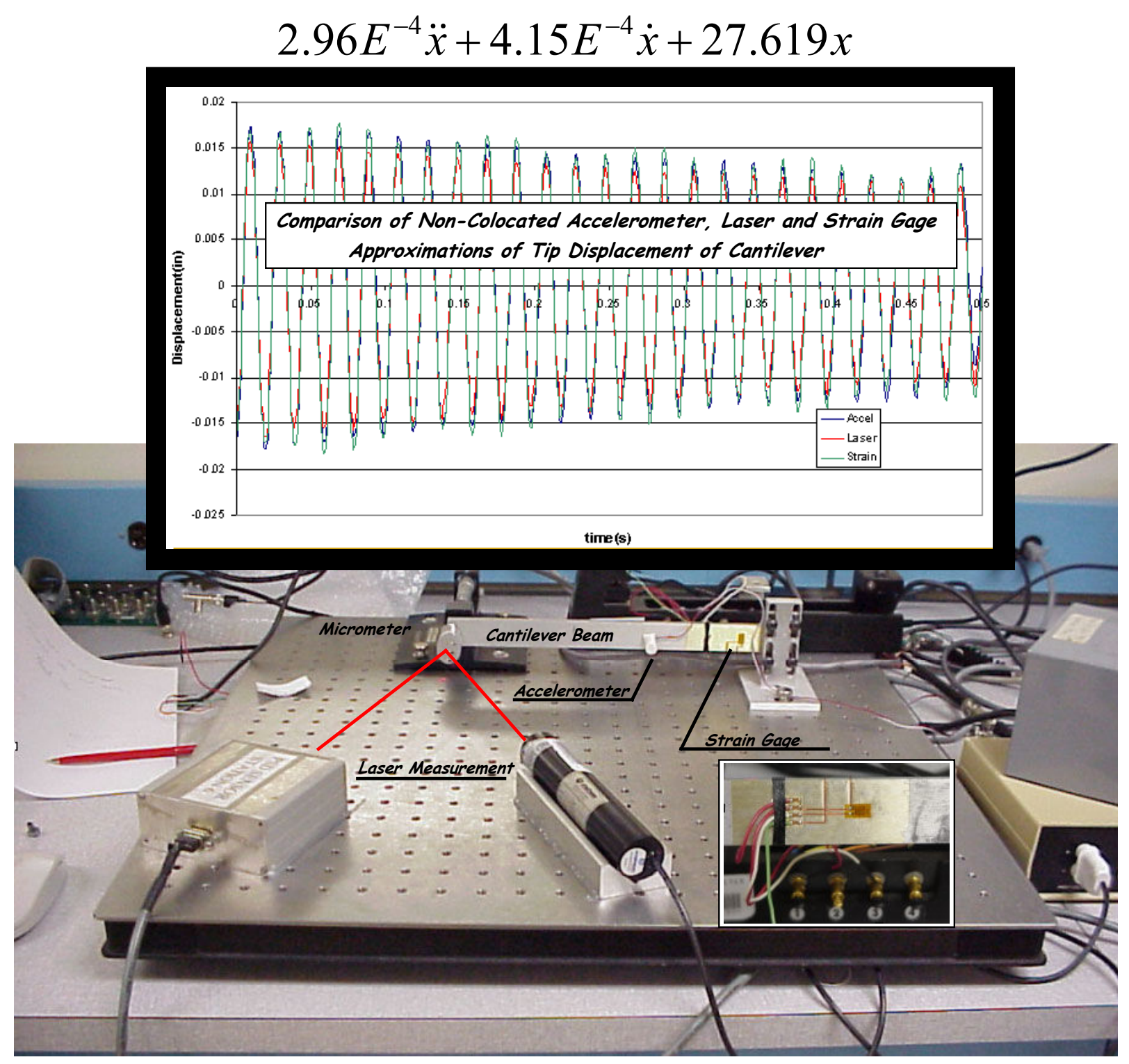

Figure 7 - Comparison of Non-Colocated Accelerometer, Laser and Strain Gage Approximations to the Tip Displacement of the Cantilever 


\section{Observations}

The students generally learn a tremendous amount of material in an integrated fashion to solve this problem. The task is not trivial. The students generally enjoy the laboratory-based, handson project. The real measurements tend to help the students clearly understand the need for basic STEM material to solve real engineering problems.

\section{Course Administrative Information}

This project has been integrated into the second semester of the Mechanical Engineering laboratory for several years now. The students are seniors when taking this required course and generally have had supporting courses such as Dynamic Systems and Numerical Methods where dynamic models have been evaluated using tools such as MATLAB and Simulink.

The laboratory time for each group is limited to 3 to 4 hour slots, once a week. Therefore, the students must do substantial "pre-work" to optimize their time available in the lab. Generally, there are 2 to 3 setups available for the AM and PM laboratory time slots, two days a week (normally Tuesday and Thursday lab times). Additional time can be scheduled upon request and availability but the students are advised to utilize their assigned times efficiently.

The project generally lasts 5 weeks at the end of the semester where students work in teams of 3 to 4 people and meet once a week with their professor to provide status, problems encountered, items to be performed next, etc. The meetings are generally conducted in an "employee/ supervisor" styled interaction. The students need to organize their material and budget time in order to complete the project. The professor's role is mainly to supervise and mentor the group. A full format report is generated and an oral presentation is given.

\section{Summary}

A complete measurement system is designed to obtain the response of a second order mechanical system. Students work in teams to measure the dynamic response at the tip of a cantilever beam using three non-colocated measurement devices. Models are developed using spreadsheet calculations, MATLAB and/or SIMULINK to aid in the determination of the dynamic system response and provide a baseline for the expected results. The students select three measurement devices from five possible types of transducers (including LVDT, accelerometer, laser, eddy current probe, and strain gage) and determine suitable locations for the transducers on the beam. They must consider signal type, transducer sensitivity, etc. to provide the "maximum" signal for the ADC to be used for data acquisition. The non-colocated measurements are then spatially adjusted and integrated/differentiated to predict the tip displacement and acceleration of the cantilever beam. A full formal report is prepared to document all aspects of the project effort along with a formal presentation. 


\section{Acknowledgement}

Some of the work presented herein was partially funded by the NSF Engineering Education Division Grant EEC-0314875 entitled "Multi-Semester Interwoven Project for Teaching Basic Core STEM Material Critical for Solving Dynamic Systems Problems". The authors are grateful for the support obtained from NSF to further engineering education.

\section{References}

1) Starrett,S., Morcos,M., "Hands-On, Minds-On Electric Power Education”, Journal of Engineering Education, Vol 90, No. 1, pp93-100, January 2001

2) Pavelich,M.J., "Integrating Piaget's Principles of Intellectual Growth into the Engineering Classroom”, Proceedings of the ASEE Annual Conference, pp719-722, 1984, Wash, DC

3) Higley,K.A., Marianno,C.M., "Making Engineering Education Fun”, Journal of Engineering Education, Vol 90, No. 1, pp105-107, January 2001

4) Davis,B.G., "Tools for Teaching”, Jossey-Bass Publishers, San Francisco, 1993, p100.

5) Piaget,J., "To Understand is to Invent", Grossman, New York, 1973.

6) Vygotsky,L., "Mind in Society: The Development of Higher Psychological Processes", Harvard University Press, MA, 1978.

7) Wolkson,A. "Employers Demand New Skills", Machine Design, Sept 1992

8) Knight,C.V., McDonald,G.H., "Modernization of a Mechanical Engineering Laboratory using Data Acquisition with LABVIEW", ASEE Session 2266

9) Onaral,B., “A Road Less Traveled”, ASEE Prism, September 1992

10) Avitabile, P., "Numerical Evaluation of Displacement and Acceleration for a Mass, Spring, Dashpot System”, ASEE 2004, Salt Lake City, June 2004

Peter Avitabile is an Assistant Professor in the Mechanical Engineering Department and the Director of the Modal Analysis and Controls Laboratory at the University of Massachusetts Lowell. He has 30 years experience in design/analysis and modeling/testing dynamic/structural systems. He is a Registered Professional Engineer with a BS, MS and Doctorate in Mechanical Engineering. He is also a member of ASEE, ASME, IES and SEM.

Charles Goodman is a Graduate Student in the Mechanical Engineering Department at the University of Massachusetts. He is currently working on his Master's Degree in the Modal Analysis and Controls Laboratory while concurrently working on an NSF Engineering Education Grant directed towards integrating STEM material critical for understanding dynamic systems response.

Tracy Van Zandt is an Undergraduate Student in the Mechanical Engineering Department at the University of Massachusetts. She will start working on hes Master's Degree in the Modal Analysis and Controls Laboratory while concurrently working on an NSF Engineering Education Grant also. 